(c) organised chaos, resulting from use of several variants of video technology, some more successful than others.

\section{Lessons}

(a) The standards and reliability of non-medical speakers are variable. It is wise to spend some time making sure that your choice will live up to expectations. Doctors are usually dependable and are almost always happy to contribute to the training of future consultants for a nominal fee and reasonable expenses, especially if personal contacts exist. Busy academics are unlikely to accept an invitation out of the blue.

(b) Sponsorship should be taken seriously. It is best to get to know your representatives and then tell them exactly what they will be getting at the event (e.g. position of stand for products, company name on literature). Costs should be carefully calculated and then an overestimate (by 25-50\%) given to sponsors well in advance. They will always be happy with an event which underspends, but not with the reverse.

(c) Camcorders. These are easy to use and give instant feedback; get acquainted with them beforehand.

\section{Let the lecturer do the work}

Both the 21st and 22nd jamborees were successful, but in very different ways. The 21 st was ambitious and elaborate, involving an organising committee of five, all of whom put in a fair amount of hard work, developing vignettes and collecting research instruments for a day on 'Research Techniques in Psychiatry'. The 22nd involved little organisation on our part as it was simply a matter of 'plugging in' to a university teaching programme on 'How to get the best from your personal computer'.

\section{Lessons}

(a) Don't be over-ambitious. Too much hard work takes its toll and invited speakers have often prepared material previously.

(b) Make use of local resources especially when they are well presented and free.

\section{Nearing perfection (?)}

In our current jamborees, senior registrars continue to make presentations of work, but closer supervision of research (as in the 19th jamboree) has now become a separate regular event in the senior registrar training overseen by the University of Bristol's Department of Mental Health.

The 23rd jamboree was problem-free and enjoyed by all, despite having a non-medical speaker and a fair amount of technology. The video workshop on 'Teaching in Small Groups' worked well. We have now moved on to plan the 24th jamboree on 'The Problems of being a Consultant'. Perhaps, after learning our lessons the hard way, we have now got things just about right.

\title{
Developing a liaison project in the community
}

\section{A. JANe Naismith, Consultant Psychiatrist, Dykebar Hospital, Paisley PA2 7DE}

It is considered valuable for senior registrars to have experience of liaison with other agencies and of setting up and evaluating projects as part of higher training in community psychiatry (Guthrie, Black \& Osborn, 1991; Royal College Of Psychiatrists Working Group, 1990). However, this may not be easy to arrange due to, for example, lack of suitable opportunities and insufficient time for initiating a project and carrying it through. Such projects are often difficult to establish and the trainee may find that a good idea founders on a variety of unexpected problems.

I will report one such experience and suggest guidelines for other trainees trying to set up projects with non-psychiatric agencies.

\section{Details of the project}

Concern had been expressed by social workers in the area about a lack of provision for the mental health needs of people from ethnic minority backgrounds. It was also felt by the local psychiatric team that the level of uptake of services did not reflect that expected given the size of the local ethnic minority population. It was agreed that a support group for young people should be started using existing staffing resources. There would be input from a community worker, a psychiatrist (myself - then a senior registrar), a bi-lingual community worker from family centre and an area social worker. 
Having joined the discussions at a later date, I thought that the reason I felt rather hazy about the details of the group was because I had missed earlier meetings and that others had these matters in hand. I understood my function as being partly in a consultative role but also with some form of treatment input to the group. I understood that the community worker would have responsibility for the more practical aspects of setting up and running the group with supervision from the social worker. After two initial planning meetings several were cancelled at short notice. Various reasons were given. I began to suspect that there were issues relating to the cancellations of which I was unaware.

Another meeting was eventually convened four months later. Only a few referrals had been received. A wide ranging discussion took place about the aims and format of the group. No conclusions were reached but it was agreed that a further meeting should be convened.

At this next meeting I suggested that the difficulty in obtaining suitable referrals might be related to the vagueness of the groups' aims and method. I added that it would be helpful to clarify our individual ideas about the group and what our roles should be in it.

It became clear that each had a different understanding of the group and his/her own role. The community worker saw his role as providing information about community facilities for group members. He envisaged a pressure group to demand services which were not already being provided. The area team social worker saw her role as being an agent to collect referrals and to pick up social work issues, e.g. child care. The bilingual community worker felt strongly that there was a need for better access to mental health services for her client group but her remit was limited to fact finding by her line managers in a voluntary agency. None envisaged an active role in running the group. I contributed my perception which was that this initiative had originated from the social work department. I understood that I was to be involved initially in a consultative role but also to provide psychiatric input as appropriate. Like the others I expected not to be primarily responsible for running the group.

We then learnt that the senior social worker who had originally suggested the group had left her post and was not to be replaced. The supervision she was to have provided for social work staff on the project would not be forthcoming from other supervisors as this was a special project and not seen as the duty of the other current senior social workers to supervise. Until this meeting no-one had raised the implications of this problem over supervision. We also heard that the resources which had been promised were no longer available. The meeting disbanded with the community worker and the social worker planning to discuss issues of supervision and resources with their superiors. These, however, remained unresolved and the project foundered.

\section{Conclusions and recommendations}

While potentially a frustrating exercise, an experience of this kind can be a learning process. Positive aspects include: contact with other non-psychiatric agencies; researching and learning about a new field of work; finding out about hazards on the way to planning a community project; learning the importance of understanding the structure of any organisation with which a joint project is to be undertaken; and learning of the importance of understanding the structure of one's own organisation and its impact on others with whom you wish to work.

\section{Proposed guidelines for trainees developing joint prospects}

(a) If joining a project mid-way through the planning stage, be very clear about its history and development. In such circumstances, ask for a written statement of the aims of the proposed project prior to your first meeting.

(b) Do not assume that everyone else knows what they are doing!

(c) Find out who is supervising the project overall, and who is supervising each individual worker. Make sure supervisors support the project and have made the necessary practical arrangements for finance and supervision.

(d) Do not proceed until satisfied that the above issues are clarified and that the proposed contribution of all participants has been clearly specified and agreed.

(e) As far as possible be in at the beginning. There is a particular problem for trainees with short placements. Some flexibility in the psychiatric training system is likely to be required to organise the time.

(f) Set out a time limit on the number and duration of meetings.

Without being defeatist or giving in too easily, it may still be valuable to make mistakes or be involved in a project while in training even if it is largely unsuccessful. Time which may be wasted in terms of service provision may provide a useful learning experience, better enjoyed as a trainee than at consultant level.

\section{Acknowledgement}

I would like to thank Dr Denise Coia for advice and support with this project.

\section{References}

Guthrie, E., Black, D. \& OSBorN, M. (1991) Careers in psychiatric specialties: Community psychiatry. Psychiatric Bulletin, 15, 94-95.

Royal College of Psychiatrists (1990) Report of the Working Group on the training implications of the move towards community orientated treatment. Psychiatric Bulletin, 14, 686-693. 